\title{
Trend of Electronic Cigarettes Papers - A Concise Analytical Review
}

\author{
Gholamreza Heydari* \\ Department of Tobacco Prevention and Control Research, Shahid Beheshti University of Medical Sciences, Iran
}

Submission: March 08, 2017; Published: October 27, 2017

*Corresponding author: Gholamreza Heydari, Tobacco Prevention and Control Research Center, National Research Institute of Tuberculosis and Lung Diseases, Shahid Beheshti University of Medical Sciences, Tehran, Iran, Email: ghrheydari@yahoo.com

Abstact

Background and objectives: The use of electronic cigarette is rapidly increasing and its safety and efficacy remain a matter of debate. This study aimed to review relevant articles to draw a conclusion regarding the trend of electronic cigarettes papers and its massages.

Methods: All articles published in PubMed-indexed journals until 2015 regarding electronic cigarette were collected. Based on the results, they were registered in a checklist under four categories of content, effects, consumption and others according to their publication date.

Results: A total of 222 articles were chosen for final review. The frequency of articles published in years 2009 to 2015 was 1, 3, 5, 14, 33, 81 and 85 , respectively. The frequency of articles categorized under effects, consumption, content and others was 101, 60, 38 and 23, respectively. Number of studies reporting positive effects compared to those reporting adverse or no effects was zero, zero, zero, 1 out of 3, 4 out of 15, 19 out of 50 and 19 out of 39 during the years 2009 to 2015, respectively.

Conclusion: Although, number of studies supporting its use had increased in the recent years but, further studies are warranted to ensure their safety and efficacy.

Keywords: Cigarette; Electronic cigarette; Complications

\section{Introduction}

Offering help to quit tobacco use and providing smoking cessation services is one of the six measures of the MPOWER policy package introduced by the World Health Organization (WHO) to control tobacco epidemics in countries that signed the WHO Framework Convention on Tobacco Control (FCTC). These services should be up-to-date, easily accessible and affordable and must be preferably provided by the health care system [1]. A wide range of smoking cessation methods are now available including pharmaceutical therapy by use of nicotine replacements such as Zyban (bupropion) and Chantix (varenicline) medications and non-pharmaceutical methods such as cognitive-behavioral therapy, instruction and training, personal quitting plans, acupuncture, hypnotism, group therapy and self-instruction. The above-mentioned methods and medications are first-line strategies based on scientific evidence [2].

Electronic Nicotine Delivery System (ENDS) was recently introduced to the market, which consists of a plastic or metal mouthpiece, a liquid nicotine reservoir, a battery and an electronic vapor producer. The user puffs on the mouthpiece and inhales a vapor mixture of different chemicals including nicotine, followed by an exhale [3]. This device was first designed for use in public places where smoking is prohibited by law and was later recommended as a solution for quitting or cutting down smoking and even as a low-harm cigarette for smokers' companions. By a significant rise in its use, 460 different types of ENDS were manufactured and marketed [4,5]. However, evidence exists regarding its adverse health effects [6,7]; the adverse health consequences related to inhalation of its second hand smoke have also been documented $[8,9]$.

Following the manufacturers' claims regarding electronic cigarette helping smoking cessation, several studies indicated its lack of success in helping smokers quit smoking $[10,11]$. Conversely, a few studies have reported short-term beneficial effects of this device in decreasing the harmful effects of actual cigarette smoking $[12,13]$. Despite the existing controversies regarding the effects of ENDS, no consensus has been reached about its use. Despite receiving no support or approval from the scientific organizations worldwide such as the European Respiratory Society, American Respiratory Society or the WHO (3), it is still extensively advertised by the media and its use is 
increasing especially among the young adults and non-smokers [14].

This study aimed to do a review on scientific articles published to reach the trend of electronic cigarette papers and its massages for having a simple conclusion regarding it.

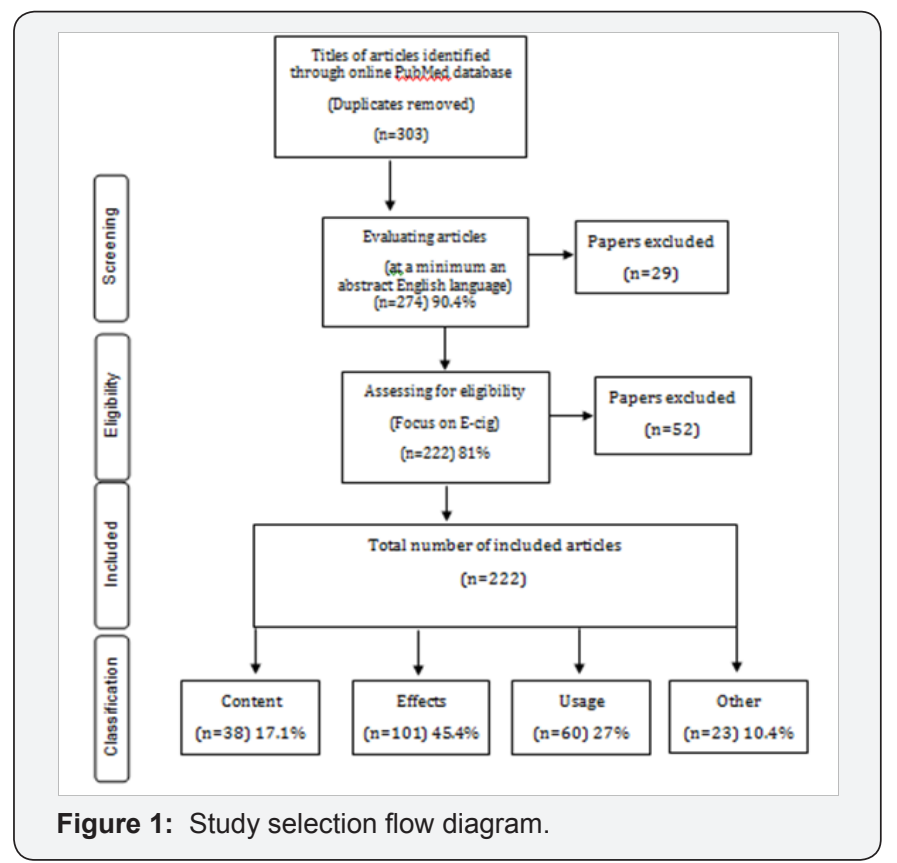

This cross-sectional study was conducted in late 2014. The PubMed database was searched for articles on electronic cigarettes published until 2014 using the keywords "electronic cigarette", "power-driven cigarette", e-cigarette", "ENDS" and "Electronic Nicotine Delivery System". Flow Figure 1 shows the process of article selection (retrieval, review, inclusion and exclusion criteria).

A checklist was designed by a panel of experts, which included date of publication, number of articles, number of accessible articles and the results of studies. The retrieved articles were coded and reviewed by two researchers separately under the supervision of the research supervisor. The researchers filled out the checklist. In case of disagreement between the two, the research supervisor reviewed the article and filled out the checklist.

In order to initially check reliability, a pilot inter-rater reliability assessment was conducted. Each reviewer assessed three randomly selected articles. The inter-rater reliability was $76 \%$ before discussion; any discrepancies in answers were discussed and a consensus was achieved on subsequent review. After the training and pilot assessment, the researchers were ready to do the literature search. The first report of the researchers was observed again by the principal investigator, who determined when the assistants were ready to work alone.

Eventually, $10 \%$ of all articles were randomly chosen for final review. Based on the type of study and its results, the studies were categorized under four groups of contents (shape and compositions), effects (complications and smoking cessation), consumption (prevalence and belief) and others (laws and regulations, sales and marketing) taking into account the publication date of studies.

\section{Results}

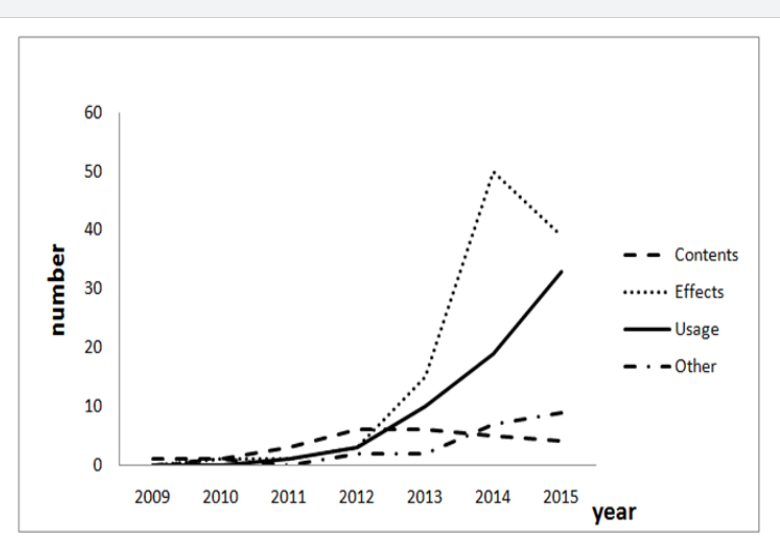

Figure 2: Frequency of the classification of electronic cigarette papers by years and subjects.

Table 1: Frequency of the classification of electronic cigarette papers by years and subjects.

\begin{tabular}{|c|c|c|c|c|c|c|c|c|}
\hline Subject & $\mathbf{2 0 0 9}$ & $\mathbf{2 0 1 0}$ & $\mathbf{2 0 1 1}$ & $\mathbf{2 0 1 2}$ & $\mathbf{2 0 1 3}$ & $\mathbf{2 0 1 4}$ & $\mathbf{2 0 1 5}$ & total \\
\hline Contents & 1 & 1 & 3 & 6 & 6 & 5 & 4 & 38 \\
\hline Effects & - & 1 & 1 & 3 & 15 & 50 & 39 & 101 \\
\hline Usage & - & - & 1 & 3 & 10 & 19 & 33 & 60 \\
\hline Other & - & 1 & - & 2 & 2 & 7 & 9 & 23 \\
\hline total & 1 & 3 & 5 & 14 & 33 & 81 & 85 & 222 \\
\hline
\end{tabular}

A total of 343 articles were retrieved; out of which, 29 (10\%) did not even have an accessible abstract. Of the remaining 274, 52 (19\%) were not exclusively about electronic cigarette and had only briefly mentioned it; thus, they did not meet our inclusion criteria and were therefore excluded. Eventually, 222 articles $(73.2 \%$ of the total) were chosen for final review, which were categorized into four groups presented in Table 1 and Figure 2 based on their publication date. Articles on the effects of electronic cigarette had the highest frequency and mainly reported the side effects of smoking cessation ( $n=101,45.4 \%$ ). Articles on sales and marketing conditions and related laws and regulations had the lowest frequency $(n=23,10.4 \%)$. None 
of the articles on the consumption rate made any comparison or mentioned anything about the reduction of use. Among articles on the effects of electronic cigarettes, number of studies reporting positive effects compared to those reporting adverse or no effects was zero, zero, zero, 1 out of 3, 4 out of 15,19 out of 50 and 19 out of 39 during the years 2009 to 2015, respectively.

\section{Discussion}

Number of studies on electronic cigarettes has noticeably increased in the recent years, which highlights the importance of this topic in health programs and concerns regarding its positive and negative health effects. Such a rise in popularity may also be attributed to extensive advertisements of this device in the media. However, Heydari, et al. [15] reported that this device was not a valuable tool for smoking cessation based on the number of studies on this topic. Another issue worthy of noting is the increasing prevalence of electronic cigarette use among the general population and particularly the young adults $[16,17]$. No study was found reporting a reduction in use of electronic cigarettes; this finding indicates the significant effect of advertisements in the media on increasing the public demand for this device regardless of its positive/negative health effects. Some studies have pointed to the interest of young adults in electronic cigarette since they truly believe that it is harmless and think of it as a safe alternative to actual cigarettes $[18,19]$. In the United Kingdom, electronic cigarette has been used for smoking cessation and has proven to be desirable even for non-smokers [20]. Electronic cigarette has also caught the attention of tobacco companies, and the British-American tobacco (BAT) company has referred to it as a giant investment [21]. For this reason, number of studies on the sales and marketing of electronic cigarettes has also increased in the recent years and many of which, have pointed to the popularity of electronic cigarette and the need for setting rules and regulations regarding its use $[22,23]$. However, studies on the use of this device for smoking cessation purposes have not reported promising results and clinicians do not recommend it as an effective method to help quit smoking [24].

Another noteworthy issue in assessment of the results of studies was an inversion in the ratio of studies rejecting electronic cigarettes to those supporting it in the recent years as in $2014,38 \%$ of articles and in $2015,48 \%$ of articles reported the electronic cigarettes to be effective. One reason may be that its beneficial effects are revealing. However, the WHO has yet to acknowledge the beneficial effects of electronic cigarette based on documentation and evidence [1-3]. Apparently, the WHO still needs time to reach a conclusion regarding the efficacy and safety of electronic cigarettes.

\section{Conclusion}

Despite the existing evidence regarding the inefficacy of electronic cigarettes, number of studies supporting its use has increased in the recent years. However, electronic cigarette is not yet recommended by the accredited health organizations worldwide and therefore, further studies are still required to scrutinize the safety and efficacy of this device.

\section{Contribution}

GH had the original idea, designed the study and outlined the first draft of the manuscript. FC and LF read and approved the final manuscript.

\section{References}

1. WHO (2008) Report on the Global Tobacco Epidemic, 2008: The MPOWER package. World Health Organization, Geneva.

2. Fiore MC (2007) Treating Tobacco Use and Dependence: A Public Health Service Clinical Practice Guideline. Rockville, MD: US Department of Health and Human Services, PressBriefing.

3. Zhu SH, Sun JY, Bonnevie E, Cummins SE, Gamst A, et al. (2014) Four hundred and sixty brands of e-cigarettes and counting: implications for product regulation. Tobacco Control 23: iii3-iii9.

4. Grana R, Benowitz N, Glantz SA (2014) E-cigarettes: a scientific review. Circulation 129: e490-e492.

5. Bahl V, Lin S, Xu N, Davis B, Wang Y (2012) Comparison of electronic cigarette refill fluid cytotoxicity using embryonic and adult models. Reprod Toxicol 34: 529-537.

6. Goniewicz ML, Knysak J, Gawron M, Kosmider L, Sobczak A, et al. (2014) Levels of selected carcinogens and toxicants in vapor from electronic cigarettes. Tobacco Control 23(2): 133-139.

7. Czogala J, Goniewicz ML, Fidelus B, Zielinska-Danch W, Travers MJ, et al. (2014) Secondhand exposure to vapors from electronic cigarettes. Nicotine Tob Res 16(6): 655-662.

8. McAuley TR, Hopke PK, Zhao J, Babaian S (2012) Comparison of the effects of e-cigarette vapor and cigarette smoke on indoor air quality. Inhal Toxicol 24(12): 850-857.

9. Bullen CB, Howe C, Laugesen M, McRobbie H, Parag V, et al. (2013) Electronic cigarettes for smoking cessation: a randomized controlled trial. Lancet 382(9905): 1629-1637.

10. Brown J, Beard E, Kotz D, Michie S, West R (2014) Real-world effectiveness of e-cigarettes when used to aid smoking cessation: a cross-sectional population study. Addiction 109(9): 1531-1540.

11. Etter JF, Bullen C (2011) Electronic cigarette: users profile, utilization, satisfaction and perceived efficacy, Addiction 106(11): 2017-2028.

12. Polosa R, Caponnetto P, Morjaria JB, Papale G, Campagna D, et al. (2011) Effect of an electronic nicotine delivery device (e-Cigarette) on smoking reduction and cessation: a prospective 6-month pilot study. BMC Public Health 11: 786.

13. Giovenco DP, Lewis MJ, Delnevo CD (2014) Factors associated with e-cigarette use. American Journal of Preventive Medicine.

14. Heydari G, Masjedi M, Ebnahmady A, Leischow S J, Lando HA, et al. (2014) Shadmehr MB, Fadaizadeh L, A Comparative study on tobacco cessation methods a quantitative systematic review. Int J Prev Med 5(6): 673-678.

15. Corey C, Wang B, Johnson SE, Apelberg B, Husten C, et al. (2013) Notes from the field: electronic cigarette use among middle and high school students - United States, 2011-2012. Morbidity and Mortality Weekly Report 62(35): 729-730.

16. Lee S, Grana RA, Glantz SA (2013) Electronic cigarette use among Korean adolescents: a cross-sectional study of market penetration, dual use, and relationship to quit attempts and former smoking. Journal of Adolescent Health 54(6): 684-690. 
17. Goniewicz ML, Zielinska-Danch W (2012) Electronic cigarette use among teenagers and young adults in Poland. Pediatrics.

18. (2016) ASH UK fact sheet Use of electronic cigarettes in Great Britain.

19. West R, Brown J, Beard E (2014) Smoking toolkit study. Trends in electronic cigarette use in England.

20. Evans P (2014) E-cigarettes are the future? Not so fast, says BAT's boss. Wall Street Journal.

21. Prior A (2014) Lorillard profit down as e-cigarette sales drop: electronic cigarette sales tumble $35 \%$, offsetting slight increase in traditional cigarettes. Wall Street Journal.

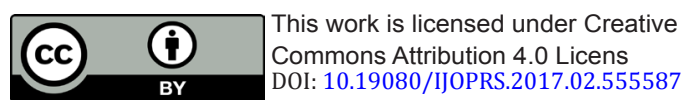

22. Wile R (2014) Citi e-cigarettes: the e-cigarette boom is over. Business Insider.

23. Heydari G, Masjedi M, Ahmady AE, Leischow SJ, Harry AL, et al. (2015) Assessment of Different Quit Smoking Methods Selected by Patients in Tobacco Cessation Centers in Iran. Int J Prev Med 6: 81.

24. Heydari G, Masjedi M, Ebn Ahmady A, Leischow SJ, Lando HA, et al. (2015) Quit Smoking Experts' Opinions toward Quality and Results of Quit Smoking Methods Provided in Tobacco Cessation Services Centers in Iran. Int J Prev Med 6: 74.

\begin{tabular}{l} 
Your next submission with Juniper Publishers \\
will reach you the below assets \\
- Quality Editorial service \\
- Swift Peer Review \\
- Reprints availability \\
- E-prints Service \\
- Manuscript Podcast for convenient understanding \\
- Global attainment for your research \\
- Manuscript accessibility in different formats \\
( Pdf, E-pub, Full Text, Audio) \\
- Unceasing customer service \\
Track the below URL for one-step submission \\
https://juniperpublishers.com/online-submission.php \\
\hline
\end{tabular}

